\title{
MINI-ESTAQUIA DE MAMOEIRO 'GOLDEN' UTILIZANDO AIB NA INDUÇÃO AO ENRAIZAMENTO, EM SISTEMA SEMI-HIDROPÔNICO
}

\author{
Omar Schmildt ${ }^{1}$ \\ Edilson Romais Schmildt ${ }^{2}$ \\ Geraldo Antônio Ferreguetti ${ }^{3}$ \\ Márcio José Vieira de Oliveira ${ }^{4}$ \\ Rodrigo Sobreira Alexandre ${ }^{5}$
}

Resumo: Objetivou-se com este trabalho, realizado em sistema semi-hidropônico, avaliar a influência do ácido indol-3-butírico (AIB) no enraizamento de mini-estacas de mamoeiro hermafrodita 'Golden'. O delineamento adotado foi inteiramente casualizado, com 4 repetições, sendo cada uma delas constituída de 6 estacas. Os tratamentos foram constituídos de 5 níveis de $A I B$ (0; 3; 6; 9 e $12 \mathrm{mg} \mathrm{L}^{-1}$ ). Aos 60 dias de cultivo, as mini-estacas foram avaliadas quanto à porcentagem de enraizamento e sobreviventes, comprimento da maior raiz, número de folhas e a altura. Conforme os resultados encontrados, verifica-se que níveis de AIB entre 9 e 12 mg L L propiciaram melhor a indução ao enraizamento de mini-estacas de mamoeiro 'Golden', em todas as características avaliadas, sendo portanto, indicado o nível de $9 \mathrm{mg} \mathrm{L}^{-1}$ de $A I B$, visando a redução de custos.

Palavras-chave: Carica papaya; ácido indol-3-butírico; hermafrodita; propagação vegetativa.

\footnotetext{
'Dr. em Produção Vegetal pela Universidade Estadual do Norte Fluminense Darcy Ribeiro. Bolsista PNPD/CAPES na Universidade Federal do Espírito Santo, Brasil. E-mail: omarschmildt@gmail.com.

${ }^{2}$ Dr. em Genética e Melhoramento pela Universidade Federal de Viçosa. Prof. na Universidade Federal do Espírito Santo, Brasil.E-mail: e.romais.s@gmail.com.

${ }^{3}$ Graduado em Agronomia pela Universidade Federal do Espírito Santo. Diretor Executivo na empresa Caliman Agrícola SA, Brasil. E-mail: geraldo@caliman.com.br.

${ }^{4}$ Dr. em Produção Vegetal pela Universidade Federal do Espírito Santo. Técnico no Instituto Federal do Espírito Santo/Campus de Alegre, Brasil. E-mail: marciojvoli@hotmail.com.

${ }^{5}$ Dr. em Fitotecnia pela Universidade Federal de Viçosa. Prof. na Universidade Federal do Espírito Santo, Brasil. E-mail: rodrigosobreiraalexandre@gmail.com.
} 